\title{
Application Features of the Engineering Seismometric Method of Survey and Monitoring the Technical Condition of Buildings and Structures
}

\author{
Aleksandr P. Kuzmenko*, Vladimir S. Saburov, \\ Leonid A. Korolenko and Daria B. Korolenko \\ Institute of Computational Technologies of SB RAS \\ 6 Academician M.A. Lavrentiev, Novosibirsk, 630090, Russia
}

Received 11.09.2018, received in revised form 03.12.2018, accepted 01.02.2019

This paper considers the history of the development and using the engineering seismometric method of the examination and monitoring of buildings and structures for various purposes. The sequence of seismometric surveys and the justification of the process of periodic or continuous monitoring the technical condition by the changing of dynamic and elastic characteristics of the object is shown. Based on the long-term work experience, the authors presented the main mistakes made during the seismometric surveys and monitoring the technical condition of buildings and structures.

Keywords: engineering seismometric method, monitoring the technical condition, frequency of forms of natural vibrations, identification of natural vibrations forms, seismic events, dynamic and elastic characteristics.

Citation: Kuzmenko A.P., Saburov V.S., Korolenko L.A., Korolenko D.B. Application features of the engineering seismometric method of survey and monitoring the technical condition of buildings and structures, J. Sib. Fed. Univ. Eng. technol., 2019, 12(2), 231-239. DOI: 10.17516/1999-494X-0132.

(C) Siberian Federal University. All rights reserved

This work is licensed under a Creative Commons Attribution-NonCommercial 4.0 International License (CC BY-NC 4.0)

* Corresponding author E-mail address: apkuzm@gmail.com 


\title{
Особенности применения
}

\section{инженерно-сейсмометрического метода обследования и мониторинга технического состояния зданий и сооружений}

\author{
А.П. Кузьменко, В.С. Сабуров, \\ Л.А. Короленко, Д.Б. Короленко \\ Институт вычислительных технологий СО РАН \\ Россия, 630090, Новосибирск, пр. Академика Лаврентьева, 6
}

В статье рассмотрена история развития и использования инженерно-сейсмометрического метода обследования и мониторинга зданий и сооружений различного назначения. Показана последовательность проведения сейсмометрических обследований и обоснование прочесса периодического или непрерывного мониторинга технического состояния по изменению динамических и упругиххарактеристикобъекта. Наосноведлительного опыта работы авторов представлены основные допускаемые при проведении сейсмометрических обследований и мониторинге технического состояния зданий и сооружений ошибки.

Ключевые слова: инженерно-сейсмометрическийметод, мониторинг технического состояния, частоты форм собственных колебаний, идентификаиия, сейсмические события, динамические и упругие характеристики.

Авторами совместно с сотрудниками организаций: Алтае-Саянской опытно-методической сейсмологической экспедиции, Геофизической службы СО РАН, филиала Института геологии и геофизики (г. Улан-Удэ), Югорского НИИ информационных технологий и Конструкторскотехнологического института вычислительной техники СО РАН разработан эффективный неразрушающий инженерно-сейсмометрический метод оценки и мониторинга технического состояния зданий и сооружений. Данный метод позволяет оценивать и контролировать техническое состояние зданий и сооружений по динамическим характеристикам их колебаний. Метод (способ) запатентован в РФ $[1,2]$. Подробное описание метода, основанного на использовании комплексной передаточной функции между колебаниями в опорном и пунктах наблюдения, приведено в $[3,4]$.

За период с 1998 г. авторами (или при их участии) осуществлено сейсмометрическое обследование около восьми десятков зданий различного назначения (Россия, Германия, Швейцария), плотин гидроэлектростанций: арочно-гравитационной Саяно-Шушенской, гравитационной Красноярской и контрфорсной Зейской.

Кроме того, обследованы автодорожные мосты в г. Новосибирске (р. Иня), в г. Тюмени (р. Тура), в г. Ханты-Мансийске (мост через Байбалаковскую протоку), вантовый пролет моста в районе г. Сургута (р. Обь).

Известные методы неразрушающего контроля и диагностики состояния строительных конструкций - механические, ультразвуковые и т.п. - позволяют определить физико-механические свойства строительных материалов и пород основания в ограниченной зоне проведения измерений и осуществить дефектоскопию конструкций. Для нахождения интегральных упругих характеристик, необходимых для оценки устойчивости массивных конструкций сооружений, эти методы практически непригодны. 
Рассматриваемый инженерно-сейсмометрический метод (далее кратко сейсмометрический) обследования позволяет определить с необходимой точностью динамические характеристики колебаний сооружения и оценить посредством использования замещающих аналитических моделей упругие характеристики здания или сооружения и подстилающего грунта, отображающие их техническое состояние.

Разработка сейсмометрического метода начата в 1994 г. в Новосибирской опытнометодической вибросейсмической экспедиции, где трудились авторы. На начальном этапе были разработаны методы определения динамических характеристик и оценки технического состояния зданий и сооружений (интегральной жесткости конструкции) по изменению частот собственных колебаний. В процессе апробации метода при проведении обследований конструкций разного назначения авторами предложена методика определения для зданий и сооружений интегральных величин динамического модуля упругости (модуля Юнга) и коэффициента Пуассона по скоростям распространения упругих волн с поляризацией в основных осях сооружения [5]. Способ определения скоростей без использования специальных источников вибраций является составной частью сейсмометрического метода.

Посредством совместного использования амплитудных спектров, спектров передаточных функций, коэффициента когерентности, коэффициента бегучести волны была усовершенствована методика идентификации частот и форм собственных колебаний плотин с определением типа наблюдаемых деформаций: сжатия-растяжения, изгиба, сдвига, изгибно-сдвиговых [6].

На следующем этапе была осуществлена разработка методики выбора и применения аналитических замещающих моделей сооружения, которая по рядам частот форм собственных пространственных колебаний позволяет оценивать величины упругих характеристик сооружения и его основания (жёсткости сечения сооружения относительно сдвига, изгиба, жёсткости основания относительно угловых перемещений, поперечного (вертикального) сдвига и т.п.).

На основе работ А.М. Ахтямова [7] показана единственность решения обратной спектральной задачи - определения упругих характеристик по рядам частот форм собственных пространственных колебаний для аналитических замещающих моделей сооружения в виде стержня (балки) с различными граничными условиями.

Обследование зданий и сооружений неразрушающим инженерно-сейсмометрическим методом предусматривает следующее:

1. Разработку схемы натурных наблюдений с одним или несколькими опорными пунктами на основании чертежей строительной конструкции с учетом состояния сооружения и задач обследования.

2. Проведение измерений микроколебаний обследуемого строительного объекта под воздействием микросейсмических шумов техногенного и естественного происхождения и динамических нагрузок от функционирующего на объекте оборудования без использования какихлибо специальных источников возбуждения вибраций (импульсных, вибрационных и т.п.) согласно схеме натурных наблюдений.

3. Определение в результате обработки регистрационных записей динамических характеристик обследуемого строительного объекта (частот и форм собственных колебаний, диссипативных характеристик, скоростей распространения упругих волн заданной поляризации и т.п.).

$$
-233-
$$


4. Сравнение полученных динамических характеристик с расчетными или полученными ранее при первичном сейсмометрическом обследовании.

5. Выбор аналитической замещающей модели обследуемого строительного объекта с учетом рядов спектров форм собственных колебаний по трем основным осям сооружения и осуществление на ее основе оценки технических параметров объекта (упругих характеристик конструкции и основания, степени износа, несущей способности и т.п.).

6. Выдачу заключения о техническом состоянии обследуемого строительного объекта, которое включает изменение технического состояния с учетом расчетных или полученных ранее при обследовании величин.

Разработанный сейсмометрический метод оценки и мониторинга технического состояния зданий и сооружений [1] является существенным дополнением к неразрушающим методам детального инструментального обследования строительных конструкций зданий и сооружений, проводимых в соответствии с СП 13-102-2003 (п. 5.2, п. 9.7).

Сейсмометрический метод полностью соответствует требованиям нормативных документов по мониторингу и оценке технического состояния плотин: N 117-Ф3 “О безопасности гидротехнических сооружений”, “Типовой динамический паспорт гидротехнических сооружений электростанций и инструкция по его заполнению" и зданий различного назначения: ГОСТ P 22.1.12-2005, ГОСТ 319-37-2011, ГОСТ Р 54859-2011.

На основе сейсмометрического метода разработана методика мониторинга технического состояния плотин и мостовых сооружений по изменению их динамических характеристик во времени. По результатам обследования плотин ГЭС и мостов обоснованы параметры аппаратуры для мониторинга и регистрации землетрясений, выбор схем наблюдения по результатам сейсмометрического обследования и нормативным документам и т.п. [4, 8, 9].

Методика мониторинга была апробирована на плотине Красноярской ГЭС. В 2010 г. была разработана и установлена автоматизированная система регистрации землетрясений и мониторинга технического состояния плотины Красноярской ГЭС [10]. По результатам работы системы опубликованы статьи, в которых подробно представлены результаты исследования уровня вибраций плотины в зависимости от количества функционирующих агрегатов [11], исследованы сезонные изменения динамических характеристик плотины в зависимости от УВБ, средней температуры воздуха и т.п. [12].

На примере данных обследования плотины Саяно-Шушенской ГЭС подробно рассмотрен вопрос идентификации форм собственных колебаний плотин. Обоснована необходимость осуществления обязательного первичного обследования плотин при минимальном и максимальном уровнях верхнего бьефа (УВБ) для идентификации частот собственных форм по основным осям сооружения [6].

Учитывая длительный опыт работы, следует отметить основные допускаемые ошибки при проведении сейсмометрических обследований и мониторинга зданий и сооружений.

1. Системы мониторинга зданий и сооружений устанавливают без первичного детального сейсмометрического обследования по плотной сетке наблюдения и идентификации всех значимых форм собственных колебаний по трем взаимно перпендикулярным направлениям. Причем, например, для плотин ГЭС необходимо определить частоты форм собственных колебаний при минимальном и максимальном уровнях верхнего бьефа и определить, таким 
образом, диапазон изменения частот от УВБ, который составляет приблизительно от 5 до $10 \%$.

Кроме того, знание частот и форм собственных колебаний позволяет выбрать оптимальные схемы наблюдения при разработке систем периодического или непрерывного мониторинга объекта, т. е. обеспечить при минимальном уровне затрат выделение всех значимых частот собственных форм.

Без детального обследования невозможно по небольшому количеству стационарных пунктов наблюдения системы мониторинга произвести достоверную идентификацию частот форм собственных колебаний объекта в процессе его эксплуатации.

2. Не производят за первый годовой цикл наблюдений изучение сезонных изменений динамических характеристик здания или сооружения в зависимости от температуры окружающего воздуха, промерзания грунта, льда на реке, изменения УВБ (для плотин). Изменения параметров внешних воздействий влияют на граничные условия в основании сооружения и свойства строительных материалов. Например, перепад температуры окружающего воздуха для мостовых сооружений приводит к изменению частот собственных колебаний стальных и железобетонных пролетных строений из-за изменения свойств материалов.

3. При разработке систем мониторинга используют непрерывный режим записи микроколебаний сооружения без выделения сейсмических событий в режиме, близком реальному времени, и периодических записей для мониторинга. Это приводит через несколько лет к большому объему регистрационных записей (несколько ТБ), сохранность которых нужно поддерживать, т. е. обеспечивать периодически перезапись данных на новые накопители. Более того, если отсутствует программа выделения сейсмических событий, эти записи в дальнейшем необходимо обрабатывать с применением специализированной программы достоверного выделения событий. Для осуществления периодического мониторинга из непрерывных записей необходимо будет нарезать файлы с сеансами мониторинга, как указано ниже.

При этом не учитывают длительность жизненного цикла здания или сооружения. Например, плотины ГЭС рассчитаны на длительную эксплуатацию - в течение 100 лет и более. То есть процесс деградации конструкции достаточно медленный. Как показывает опыт, для контроля воздействий сезонных изменений УВБ или температурного фактора на плотины ГЭС в процессе штатной эксплуатации достаточно производить записи микроколебаний мониторинга два раза в сутки. Это подтверждено 8-летним периодом эксплуатации автоматизированной системы сейсмометрического контроля (АССК) Красноярской ГЭС. На случай чрезвычайных ситуаций предложено осуществлять непрерывную регистрацию микроколебаний объекта в течение заданного оператором времени с последующим удалением.

4. Для выделения сейсмических событий (землетрясений) автоматизированной системой сейсмометрического контроля необходимо использовать широко применяемые алгоритмы [13].

Известны различные алгоритмы выделения сейсмических событий:

А) Самый простой алгоритм выделения сейсмических событий - триггер порога амплитуды. Задается порог по амплитуде сейсмического сигнала, при превышении которого включается запись события (порог может быть по амплитуде перемещений, скорости или ускорения в зависимости от типа используемых датчиков). Этот алгоритм применяется только для выде-

$$
-235-
$$


ления событий большой интенсивности, когда сейсмические шумы существенно ниже амплитуды событий. Алгоритм имеет большую вероятность записи «ложных» событий небольшой интенсивности.

Б) Другой алгоритм - триггер порога по среднеквадратичному значению сейсмического сигнала в коротком временном окне вместо порога по амплитуде. Однако этот алгоритм очень редко применяется на практике.

В) Известен алгоритм выделения (детектирования) сейсмических событий STA/LTA (Short Time Average to Long Time Average), основанный на анализе отношения амплитуд (или среднеквадратичных значений) в коротком и длинном временных окнах, которым моделируется отношение сигнал-шум [13]. Этот алгоритм обычно используется в сейсмологических станциях сейсмологических служб разных стран (например, станция REFTEK и др.) В алгоритме детектирования событий задаются следующие параметры:

- триггер - порог отношения амплитуд в коротком и длинном временных окнах STA/ LTA, при котором включается запись сейсмических событий;

- детриггер - порог отношения STA/LTA, при котором выключается запись сейсмических событий;

- длина регистрационной записи до обнаружения события по алгоритму позволяет не пропустить вступления продольных волн с отношением STA/LTA меньше порогового;

- длина регистрационной записи после обнаружения события по алгоритму позволяет зафиксировать волны землетрясения, амплитуда которых меньше, чем пороговый уровень;

- количество каналов системы мониторинга с превышением порога STA/LTA, после достижения которых система запускается на запись сейсмических событий.

При этом для разных каналов можно устанавливать различные значения порога с учетом уровня шумов в пунктах наблюдения. Например, в пунктах, расположенных вблизи гидроагрегатов, значения порога срабатывания можно задать выше, чтобы система не срабатывала при пуске или останове гидроагрегатов, а в тихих местах, например в области береговых примыканий плотин, порог можно установить существенно ниже.

Необходимо отметить, что настройка параметров детектирования сейсмических событий в реальных условиях штатного функционирования оборудования различных ГЭС при наличии мощных помех от функционирования, пуска или останова гидроагрегатов является сложной задачей, требующей достаточно длительного времени для оценки уровня и частотного состава шумов во времени.

Правильная настройка указанных параметров детектирования позволяет выделять на плотине локальные и региональные события с минимальным количеством ложных срабатываний системы.

5. При разработке мобильных и стационарных АССК не используются аналоговые фильтры нижних частот, что приводит к высокому уровню высокочастотных шумов на записях.

Обычно выбирают частоту оцифровки сигнала, не кратную $2^{\mathrm{n}}$, что приводит к дополнительным трудностям обработки сигналов с использованием быстрого преобразования Фурье (необходимости выбора дробного времени сеанса регистрации, добавления или вырезания 
лишних отсчетов и т.п. для получения последовательности записи, по длине равную степени двойки). Недостаточный набор коэффициентов усиления в аппаратуре мониторинга или обследования приводит к снижению точности расчета комплексных передаточных функций, где производится деление произведений комплексных спектров в опорном пункте и пунктах наблюдения [2].

6. Учитывая, что в системе обработки данных мониторинга используются алгоритмы вычисления комплексных передаточных функций (осуществляется операция деления спектров), необходимо обеспечить погрешность синхронизации при регистрации сейсмических данных не более 10 мкс.

Длина записи сеансов мониторинга должна быть длительностью не менее 5-10 мин для обработки данных посредством вычисления спектров накопления (амплитудных и передаточных функций).

7. Использование для регистрации сейсмических сигналов пьезодатчиков с интегратором внутри для получения на выходе скорости перемещения приводит к сильному подъему значений спектральной плотности на низких частотах, особенно с учетом наличия смещения нуля в усилителях постоянного тока. Если требуется регистрировать скорости перемещения в пунктах наблюдения, то лучше использовать в качестве сейсмических датчиков электроиндукционные датчики, например CM-3KB, GS-1 SeisMonitor и т.п.

Иногда пытаются по записям ускорения в пунктах наблюдения вычислять перемещения посредством двойного интегрирования записей ускорения во временной или спектральной области, что приводит к получению недостоверных данных.

Вопросы, требующие решения при дальнейшем развитии инженерно-сейсмометрического метода:

- Обоснование выбора аналитических замещающих моделей для зданий и сооружений различного назначения и методов решения обратной спектральной задачи с учетом обеспечения однозначности решения обратной задачи.

- Определение границ изменения динамических и упругих характеристик обследуемого объекта (предельно допустимых значений), превышение которых требует капитального ремонта или вывода из эксплуатации и внесение этих параметров в соответствующие нормативные документы.

\section{Список литературы}

[1] Патент № 2140625 Российская Федерация, МПК7 G01M 7/00. Способ определения физического состояния зданий и сооружений. Селезнёв В.С., Еманов А.Ф., Барышев В.Г., Кузьменко А.П., заявитель и патентообладатель авторы, 98102539/03 рег. 17.02.98 [Patent № 2140625 Russian Federation, MPK7 G01M 7/00. The method of determining the physical condition of buildings and structures. Seleznev V.S., Emanov A.F., Baryshev V.G., Kuzmenko A.P., applicant patent holder of authors, 98102539/03 reg. 17.02 .98 (in Russian)]

[2] Патент № 2150684 Российская Федерация, МПК7 G01M 7/00. Способ приведения к единому времени регистрации разновременных записей измерений. Селезнёв В.С., Еманов А.Ф., Барышев В.Г., Кузьменко А.П., Сабуров В.С., заявитель и патентообладатель авторы, 98102539/03 рег. 26.08.98. [Patent № 2150684 Russian Federation, MPK7 G01M 7/00. The method of reducing 
the registration of multi-time measurement records to a single time. Seleznev V.S., Emanov A.F., Baryshev V.G., Kuzmenko A.P., Saburov V.S., applicant patent holder of authors, 98102539/03 reg. 08.26.98 (in Russian)]

[3] Сабуров В.С., Кузьменко А.П. Обследование зданий повышенной этажности. Инженерно-сейсмометрический метод. LAMBERT Academic Publishing, 2013, 184 с. [Saburov V.S., Kuzmenko A.P. Survey of high-rise buildings. Engineering seismometric method, Saarbrucken, LAMBERT Acad. Publ., 2013, 184 p. (in Russian)]

[4] Кузьменко А.П., Сабуров В.С. Обследование плотин гидроэлектростаниий. Инженерносейсмометрический метод (часть 1), Новосибирск, ИВТ СО РАН, 2017, 206 с. (ISBN 978-59905791-4-9). [Kuzmenko A.P., Saburov V.S. Survey of hydroelectric dams. Engineering seismometric method (part 1), Novosibirsk, ICT SB RAS, 2017, 206 p. (in Russian)]

[5] Кузьменко А.П., Сабуров В.С. Определение упругих свойств бетона плотин ГЭС по скоростям сейсмических волн. Известия ВНИИГ им Б.Е. Веденеева, 2006, 245, 259-269 [Kuzmenko A.P., Saburov V.S. Determination of the elastic properties of concrete hydroelectric dams by the speed of seismic waves. Izv. VNIIG im. B. E. Vedeneeva, 2006, 245, 259-269 (in Russian)].

[6] Кузьменко А. П. Сабуров В.С. Идентификация форм собственных колебаний при сейсмометрическом обследовании и мониторинге плотин ГЭС. Гидротехническое строительство, 2016, 2, 28-40 [Kuzmenko A.P., Saburov V.S Identification of forms of natural oscillations in seismometric survey hydroelectric dams monitoring. Hidrotehnicheskoe stroitelstvo, 2016, 2, 28-40 (in Russian)]

[7] Ахтямов А.М. Теория идентификащии краевых условий и ее приложения. М.: Физматлит, 2009, 272 с. [Akhtyamov A.M. The theory of identification of boundary conditions and its applications. M. : Fizmatlit, 2009, 272 p. (in Russian)]

[8] Сабуров В.С., Кузьменко А.П. Оценка технического состояния мостовых сооружений посредством детальных сейсмометрических обследований. Известия ВНИИГ Им. Б.Е. Веденеева, 2017, 284, 69-81 [Saburov V.S., Kuzmenko A.P. Evaluation of the technical condition of bridge structures through detailed seismometric surveys. Izv. VNIIG im. B. E. Vedeneeva, 2017, 284, 69-81 (in Russian)]

[9] Патент № 2650812, Российская Федерация МПК, G01M 7/00. Способ мониторинга технического состояния мостовых сооружений в процессе их эксплуатации (варианты). Кузьменко А.П., Сабуров В.С. Заявитель патентообладатель ИВТ СО РАН, №2017108312 рег.18.03.2017 [Patent № 2650812, Russian Federation IPC, G01M 7/00. The method of monitoring the technical condition of bridges during their operation (options). Kuzmenko A.P., Saburov V.S. Applicant patent holder of ICT SB RAS, No. 2017108312 reg.18.03.2017 (in Russian)]

[10] Кузьменко А.П., Золотухин Е.П., Епифанов А.П., Кузьмин Н.Г. Автоматизированная система регистрации землетрясений и мониторинга технического состояния плотин гидроэлектростанций. Гидротехническое строительство, 2011, 12, 28-34 [Kuzmenko A.P., Zolotukhin E.P., Epifanov A.P., Kuzmin N.G. Automated earthquakes recording and monitoring the technical condition of hydroelectric dams system. Hidrotehnicheskoe stroitelstvo, 2011, 12, 28-34 (in Russian)]

[11] Кузьменко А.П., Сабуров В.С., Короленко Д.Б., Кузьмин Н.Г. Контроль уровня вибраций плотины Красноярской ГЭС по данным системы мониторинга. Известия ВНИИГ им. Б.Е. Веденеева, 2015, 275, 24-32 [Kuzmenko A.P., Saburov V.S., Korolenko D.B., Kuzmin N.G. 
Vibration level control of the Krasnoyarsk hydroelectric dam by monitoring system data. Izv. VNIIG im. B.E. Vedeneeva, 2015, 275, 24-32 (in Russian)]

[12] Кузьменко А.П., Сабуров В.С., Епифанов А.П., Кузьмин Н.Г. Динамические характеристики колебаний плотины Красноярской ГЭС. Гидротехническое строительство, 2010, 2, 2834 [Kuzmenko A.P., Saburov V.S., Epifanov A.P., Kuzmin N.G. Dynamic characteristics of vibrations of the Krasnoyarsk hydroelectric dam. Hidrotehnicheskoe stroitelstvo, 2010, 2, 28-34 (in Russian)]

[13] Trnkoczy A., Understanding and parameter setting of STA/LTA trigger algorithm, in IASPEI. New Manual of Seismological Observatory Practice, 2002, 2, 01-20 